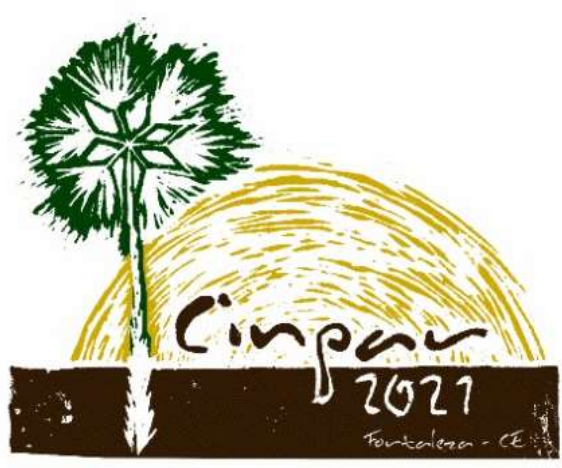

XVII Congresso Internacional sobre Patologia e Reabilitação das Construções

XVII Congreso Internacional sobre Patología y Rehabilitación de las Construcciones

XVII International Conference on Pathology and Constructions Rehabilitation

FORTALEZA (Brasil), 3 a 5 de junho de 2021

https://doi.org/10.4322/CINPAR.2021.090

\title{
ENSAIO TERMOGRÁFICO DO PATRIMÔNIO HISTÓRICO: CASA DE JOSÉ DE ALENCAR
}

\section{THERMOGRAPHIC TEST OF HISTORICAL HERITAGE: CASA DE JOSÉ DE ALENCAR}

\author{
Jennifer Braga LUZ, Ivna de Oliveira SILVEIRA, Lucas Aziz Carneiro ARY, Marcos Andrew Rabelo SOEIRO \\ ${ }^{1}$ UNIFOR, Fortaleza, Brasil, luzbjennifer@gmail.com \\ 2 UNIFOR, Fortaleza, Brasil, ivna.o.s@gmail.com \\ ${ }^{3}$ UNIFOR, Fortaleza, Brasil, lucas.aziz.ary@gmail.com \\ ${ }^{4}$ UNIFOR, Fortaleza, Brasil, marcos@duosestruturais.eng.br
}

\begin{abstract}
Resumo: O valor de um patrimônio histórico é incalculável, pois ele traz consigo a história e memórias de toda uma geração que viveu em determinada região e época. Assim para manter essas lembranças vivas na vida das pessoas é indispensável a preservação desses bens, e para ajudar na manutenção deles é imprescindível que haja vistorias constantes para que seja monitorado o estado da construção. Como se trata de um bem nacional, é importante que a inspeção não seja invasiva e que não danifique o monumento, portanto a melhor maneira de averiguar o estado de uma obra sem a deteriorar, seria por meio de um ensaio não destrutivo, no qual poderíamos analisar todo o estado do bem e diagnosticar suas possíveis patologias. A escolha pela casa de José de Alencar se deu pelo significado que o autor tem como o maior escritor romancista brasileiro e por toda a história que a edificação carrega. O ensaio escolhido para analisar o estado do patrimônio foi um não destrutivo, no caso, o termográfico, pois por ser um ensaio rápido, que abrange uma grande área e ainda não muito utilizado no Brasil, seria um estudo bem aproveitado. Ao examinar os dados, obtivemos com maior clareza quais as possíveis patologias existentes no ambiente e também descobrimos estruturas que estavam ocultas a olho nu.
\end{abstract}

Palavras-chave: patrimônio, ensaio, não destrutivo, termografia.

\begin{abstract}
The value of a historical heritage is incalculable, as it brings with it the history and memories of an entire generation that lived in a certain region and time. So to keep these memories alive in people's lives, the preservation of these assets is essential, and to help maintain them, constant inspections are essential to monitor the state of construction, as it is a national asset, it is important that the inspection is not be invasive and that it does not damage the monumento, so the best way to check the condition of a work without deteriorating it, would be through a non-destructive test, in which we could analyze the entire state of the property and diagnose its possible pathologies. The choice for José de Alencar's house was due to the meaning that the author has as the greatest Brazilian novelist writer, and for all the history that the building carries. The test chosen to analyze the state of the Heritage was a non-destructive one, in this case the thermographic test, because it is a quick test, which covers a large area and is not yet widely used in Brazil, it would be a very productive study. When examining the data, we obtained with greater accuracy which are the possible pathologies existing in the environment and we also discovered structures that were hidden to the naked eye.
\end{abstract}

Keywords: heritage, essay, non-destructive, thermography. 


\section{Introdução}

Uma saída para a pré análise das patologias em uma edificação são os ensaios não destrutivos, pois além de detectar uma possível iminente patologia que está por surgir, esses métodos de ensaios não destrutivos são melhores que os métodos mais tradicionais de ensaios destrutivos, no que se refere a manter a estrutura de estudo intacta sem nenhuma modificação.

As edificações mais antigas precisam de constante reparo e, para diagnosticar as patologias presentes nelas, o ideal seria usar técnicas que não tenham necessidade de tirar um testemunho da edificação, como em um ensaio de extração de concreto, em que é retirada uma porção do concreto na construção. Assim métodos necessários para uma pré análise são os ensaios não destrutivos.

Para uma construção antiga que foi tombada como patrimônio histórico, a preocupação fica ainda maior com a manutenção e a preservação da edificação, pois nela estão contidos memórias, registros, histórias da região e dos habitantes que ali viveram com um caráter de valores e culturas bem enraizadas.

Então se torna imprescindível o uso de técnicas de ensaios não destrutivos, que podem prevenir futuras patologias agravadas, diagnosticar o local do problema na construção de estudo e ainda podem servir como ensaios adicionais juntamente com os ensaios destrutivos.

O uso do ensaio de termografia que é um ensaio não destrutivo pode analisar grandes áreas em pouco tempo e traz um pré diagnóstico das possíveis patologias encontradas. O método vem sendo bastante utilizado na europa com normas vigentes desde a década de 1990, porém no Brasil ainda é pouco utilizada a termografia para esse fim, e por isso é necessário a criação de normas específicas para executar o estudo no país.

Assim o ensaio termográfico é ótimo para uma pré inspeção da edificação, porém não pode ser usado apenas este método para uma análise completa, por ser uma pesquisa que tem suas limitações. Contudo com o estudo de normas internacionais, e o exame de trabalhos realizados nessa temática pode se ter uma indicação de possíveis patologias e objetos ocultos na estrutura.

Todavia a combinação ensaios não destrutivos e patrimônio histórico se torna algo fundamental para a manutenção e possível investigação das causas das anomalias da edificação de estudo, sem causar danos à construção original, preservando o bem e o seu legado.

\section{Revisão bibliográfica}

\subsection{Conceito}

A termografia se baseia na radiação infravermelha. Segundo Mendonça, Amaral et al (2013), os raios caloríficos são hoje conhecidos como raios infravermelhos. Quanto mais quente está o objeto, maior é a radiação. A radiação infravermelha é sinônimo de radiação de calor.

No espectro eletromagnético encontra-se os raios infravermelhos, no vácuo essa radiação pelo observador, desloca-se na velocidade da luz. "Os humanos só conseguem enxergar uma pequena parcela do espectro eletromagnético, que se encontram no intervalo de 0,4 $\mu \mathrm{m}$ e 0,7 $\mu \mathrm{m}$ " (MENDONÇA, AMARAL et al, 2013).

Os raios infravermelhos se encontram nos intervalos de $2 \mu \mathrm{m}$ à $5 \mu \mathrm{m}$, e de $8 \mu \mathrm{m}$ à $14 \mu \mathrm{m}$, e todos esses dois intervalos estão fora do alcance da visão humana, a lacuna ao qual se encontra as câmeras termográficas utilizadas em edifícios são as de ondas longas de $8 \mu \mathrm{m}$ à $14 \mu \mathrm{m}$ (MENDONÇA, AMARAL et al, 2013).

Radiação infravermelha "faixa do espectro eletromagnético que se estende do limite inferior da radiação visível $(0,78 \mu \mathrm{m})$ até o comprimento de onda de $1000 \mu \mathrm{m}$ " (ABNT NBR 15424, 2016). 
Quadro 1 - Classificação de limites espectrais de infravermelho

\begin{tabular}{|c|c|}
\hline Classificação & Faixa de comprimento de onda \\
\hline Infravermelho próximo & $0,78 \mu \mathrm{m}-1 \mu \mathrm{m}$ \\
\hline Infravermelho de ondas curtas & $1 \mu \mathrm{m}-3 \mu \mathrm{m}$ \\
\hline Infravermelho de ondas médias & $3 \mu \mathrm{m}-6 \mu \mathrm{m}$ \\
\hline Infravermelho de ondas longas & $6 \mu \mathrm{m}-15 \mu \mathrm{m}$ \\
\hline Infravermelho de ondas muito longas & $15 \mu \mathrm{m}-1000 \mu \mathrm{m}$ \\
\hline
\end{tabular}

Fonte: (ASSOCIAÇÃO BRASILEIRA DE NORMAS TÉCNICAS, 2016)

Temos a lei de Stefan-Boltzman que define a radiação refletida de um corpo:

$$
\mathrm{W}=\sigma \cdot \varepsilon \cdot \mathrm{T}^{4}
$$

Onde:

W - Radiação emitida;

$\sigma-$ Constante de Boltzman, que é $\left(5,67^{*} 10^{\wedge}-8 \mathrm{~W} \cdot \mathrm{m}^{-2} \cdot \mathrm{K}^{\wedge}-4\right)$;

$\varepsilon-$ Emissividade;

$\mathrm{T}-$ Temperatura

Segundo Mendonça, Amaral et al (2013), existe uma lei da Física que diz que todos os materiais com uma temperatura acima do zero absoluto $(-273 \circ \mathrm{C})$ radiam calor. A radiação de calor significa o mesmo que radiação infravermelha. Quanto mais quente está o objeto, maior a radiação. Dentro da termografia há duas formas de vê-la. A termografia passiva "é caracterizada pela não utilização de um estímulo de energia artificial'” (MENDONÇA, AMARAL et al, 2013). Já na termografia ativa, "a principal característica é a aplicação de um estímulo de energia sobre o corpo" (MENDONÇA, AMARAL et al, 2013).

Assim, fica evidente que a termografia passiva é aquela na qual a energia aplicada é a luz solar, e a termografia ativa é aquela na qual é aplicada uma luz artificial com calor ou é aplicado uma fonte de energia fria para haver um diferencial térmico.

\subsection{2 - Normas}

No Brasil, não existe uma norma específica para o ensaio termográfico em edificações, mas existem normas que se relacionam ao tema:

ABNT NBR 16292/2014: Ensaios não destrutivos - Termografia - Medição e compensação da temperatura aparente refletida utilizando câmeras termográficas;

ABNT NBR 15424/2016: Ensaios não destrutivos - Termografia - Terminologia;

É perceptível que as duas primeiras normas citadas acima se enquadram com o nosso tema abordado, porém não é uma norma específica para o ensaio termográfico em um elemento de concreto ou de edificações antigas com materiais diversos. É necessário, portanto, o uso de normas internacionais adicionais para o estudo, e elaboração de normas mais atualizadas e mais específicas para o ensaio da termografia em edificações, e de construções históricas.

\subsection{3 - Trabalhos realizados}

Para o ensaio termográfico ter um caráter quantitativo, é necessário ser usada a termografia ativa, onde há o controle do meio, mas acaba sendo difícil aplicar a termografia ativa na construção histórica, visto que, devido ao tamanho da obra, não seria possível isolá-la. Assim, o método utilizado será a termografia passiva 
com a fonte de energia solar. Esse tipo de método tem um caráter qualitativo, por isso é interessante que ao aplicar o ensaio, o observador seja experiente e caso seja necessário, ele poderá usar outros métodos para complementar seu parecer técnico.

Segundo Mendonça, Amaral (2013), a termografia tem diversas aplicações nas edificações, dentre elas, a detecção de infiltrações ou fugas de água, a detecção de fendas estruturais, a detecção de vazios no interior do betão, a detecção de corrosão de armaduras, a localização de redes interiores e a análise térmica dos edifícios. O ensaio termográfico "Permite a deteç̧ão de patologias ainda não visíveis, permitindo agir mais rápido evitando que as mesmas aumentem ou se alastrem para outras localizações" (MENDONÇA, AMARAL et al, 2013).

As figuras 1, 2, 3 nos mostram diversas aplicações da termografia.
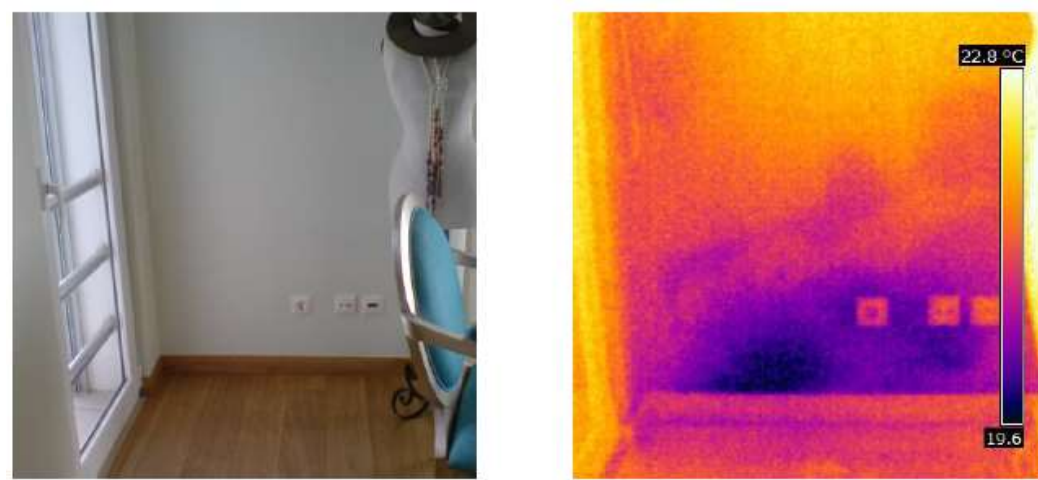

Figura 1 - Termograma detecta foco de infiltração não visível a olho nu. Fonte: (MENDONÇA, AMARAL et al, 2013).
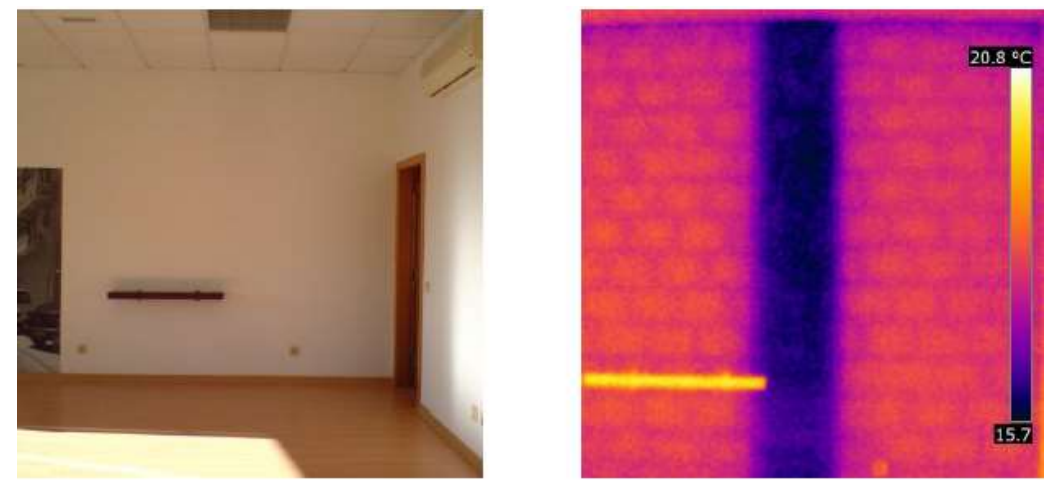

Figura 2 - Deteç̧ão de elementos estruturais, neste caso pilar. Fonte: (MENDONÇA, AMARAL et al, 2013).
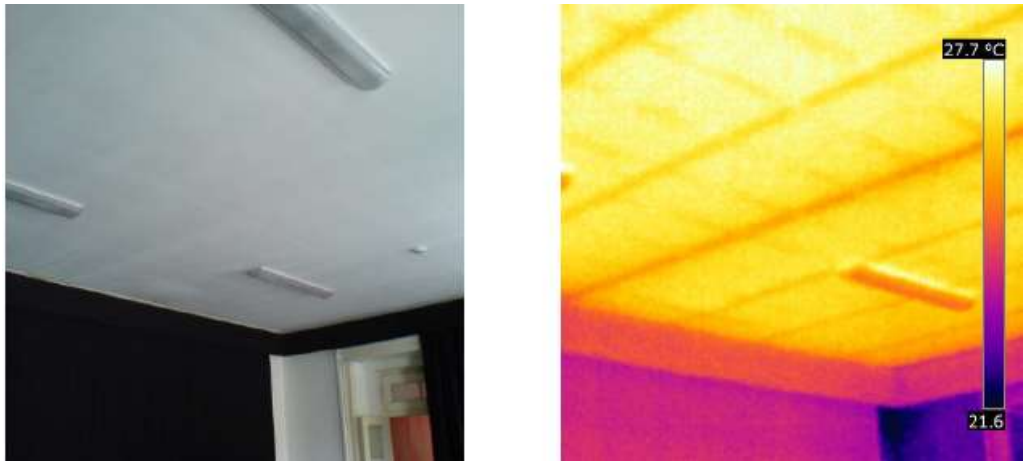
Figura 3 - Detecção de materiais diferentes que constituem o teto. Fonte: (MENDONÇA, AMARAL et al, 2013).

A termografia não precisa de outros equipamentos além da portabilidade da máquina e da forma dinâmica. Por ser um ensaio rápido, pode-se analisar áreas maiores, como edifícios altos, tornando-se uma ferramenta fundamental para a análise. "O ensaio traz muitos benefícios como localizar elementos ocultos, locais de deficiência em construção por portar pontes térmicas, e infiltrações ou condensações ocultas" (VALE, VENCESLAU et al, 2017).

Como foi citado acima, a termografia tem grande utilidade para diversos problemas como a localização de pontes térmicas (thermal brigdes, do inglês), que "são espaços responsáveis por transmitir o calor do ambiente externo para o interno" (BONAFÉ, 2020).

Geralmente onde se encontram essas pontes térmicas há o encontro de patologias, como fissuras, e são encontradas mais facilmente perto de esquadrias e de cantos na edificação.

\section{Resultados}

Por meio da câmera FLIR E6 e de uma câmera normal de fotografia, foram coletadas fotos de toda a edificação em diferentes ambientes e ângulos para detectar alguma possível patologia ou algum elemento estrutural, e talvez encontrar um dano não aparente.

Foram analisadas primeiro as fachadas e depois cada ambiente face a face.

A figura 4 mostra à direita as demarcações da diferença de material que existe nesta vista. Pode-se ver perfeitamente a guarnição e batente das esquadrias, a diferença de temperatura significativa ainda se encontra na cobertura e no piso.

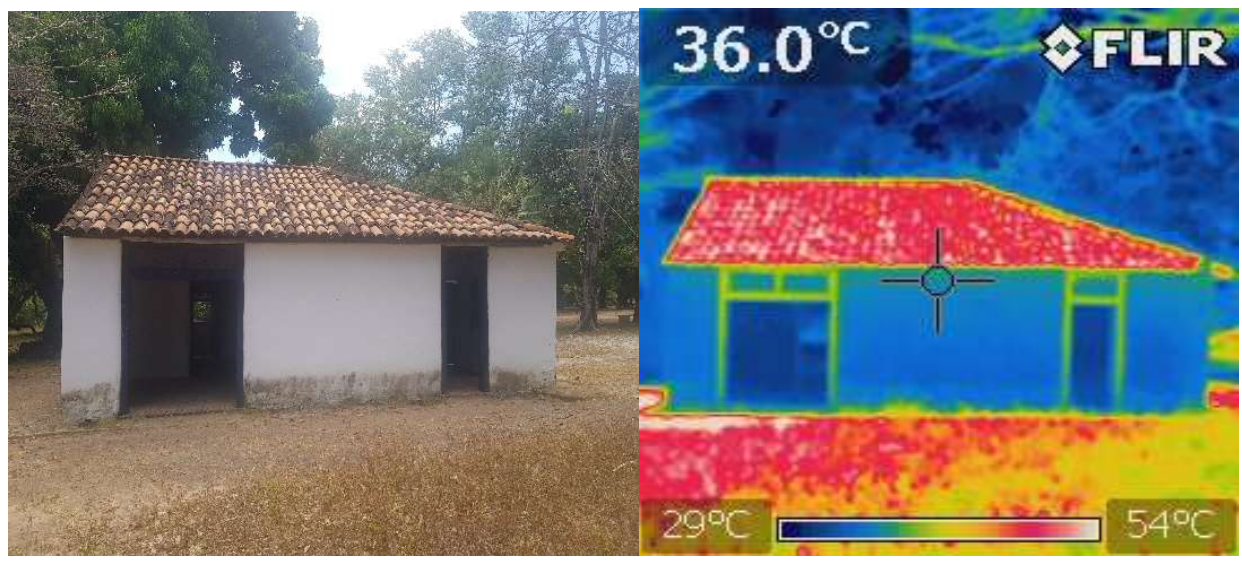

Figura 4 - Vista lateral direita nas duas perspectivas. Fonte: acervo pessoal.

Na figura 5, à direita, é possível ver uma diferença de temperatura no canto direito inferior, podendo ser foco de uma ponte térmica onde existe a transferência de calor da parte externa para a parte interna da edificação, podendo ocasionar fissuras e outros tipos de patologias.

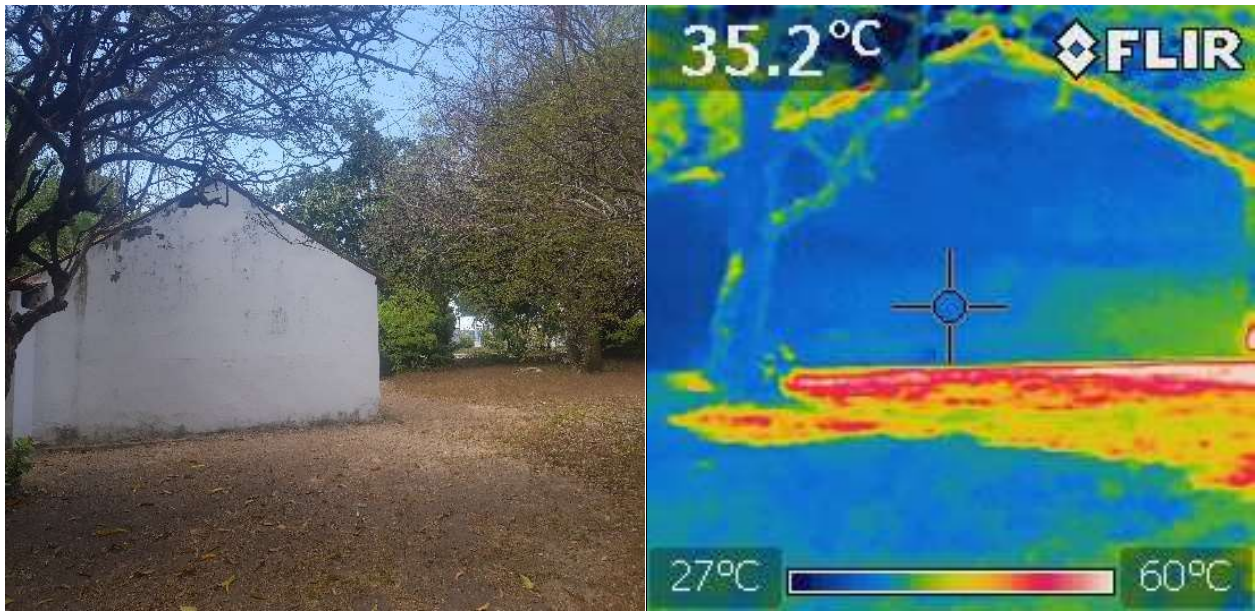


Figura 5 - Parte leste da fachada posterior nas duas perspectivas. Fonte: acervo pessoal.

A figura 6 mostra na sua parte inferior uma coloração azulada, podendo ser um futuro foco de umidade nessa parte da edificação, pois nessa parte tem uma diminuição da temperatura, mesmo que essa diferença seja pequena.

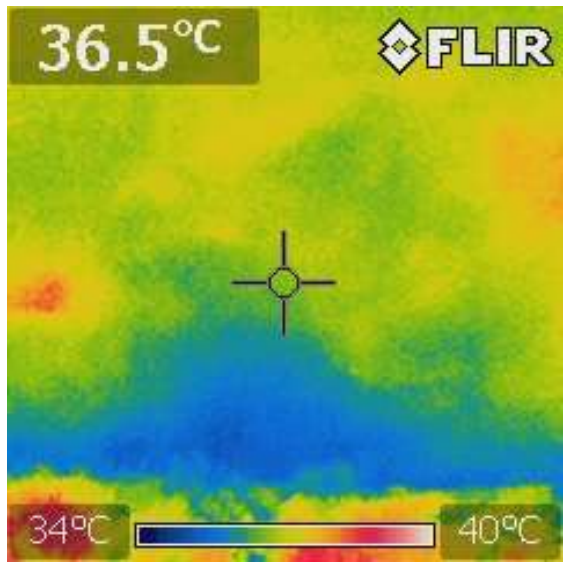

Figura 6 - Detalhe na fachada posterior na sua parte inferior. Fonte: acervo pessoal.

Pode-se ver que na figura 7, à direita, há duas faixas com azul escuro na região inferior da parede o que pode significar a presença de outro material, que não pode ser visto a olho nu, talvez possa ter sido outra intervenção feita na edificação, podendo ter sido colocado um impermeabilizante na região pra evitar umidade.

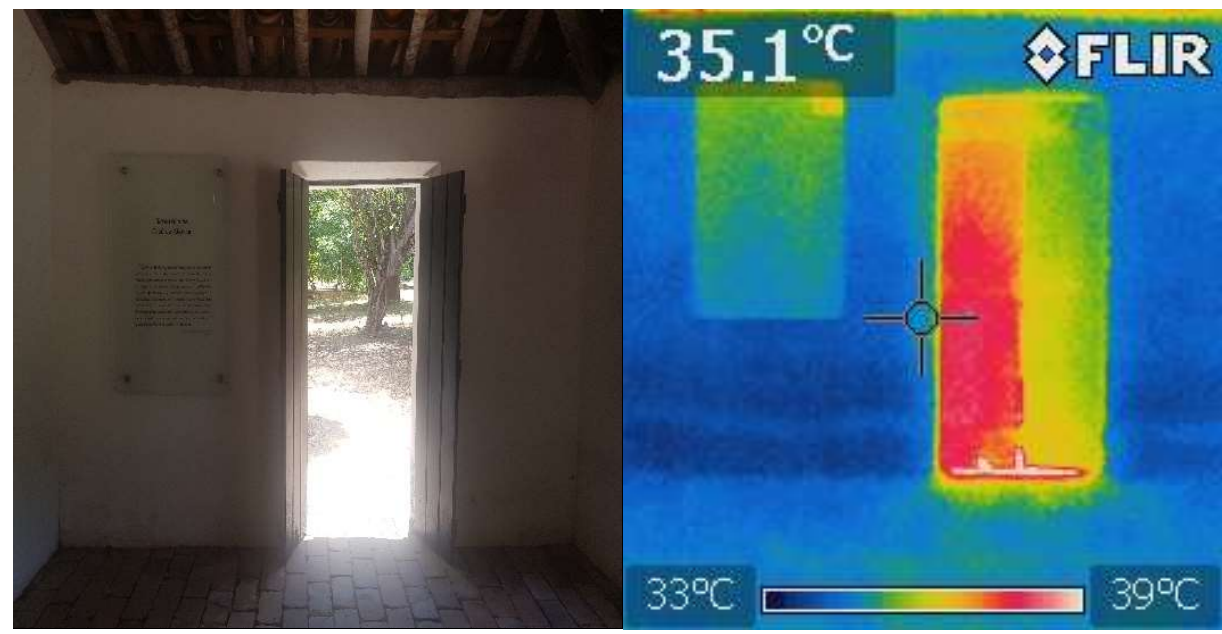

Figura 7 - Parede interna da sala de estar nas duas perspectivas. Fonte: acervo pessoal.

Esse material oculto na figura 8 pode indicar a presença de outra intervenção realizada na casa, e este elemento oculto pode ter alguma função estrutural na construção.

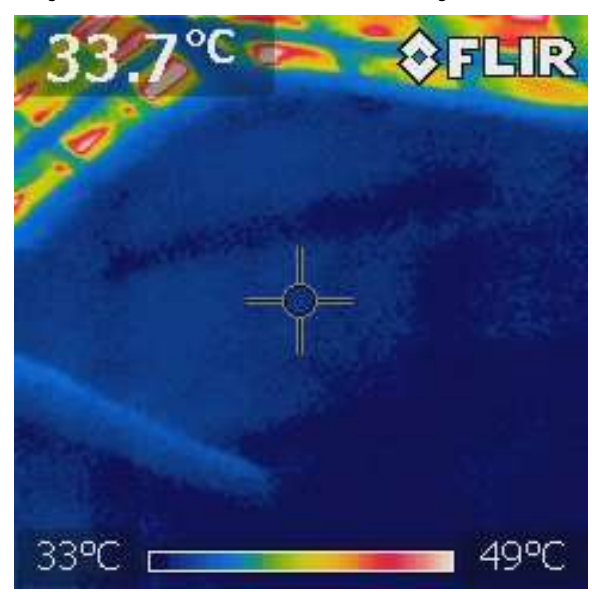

Ensaio termográfico do patrimônio histórico: Casa de José de Alencar 
Figura 8 - Parede interna entre a sala de jantar e o quarto. Fonte: acervo pessoal.

A figura 9, à direita, mostra uma região mais azul entre o vão da janela, que indica o desnível que existe na parede, como revela a figura à esquerda.

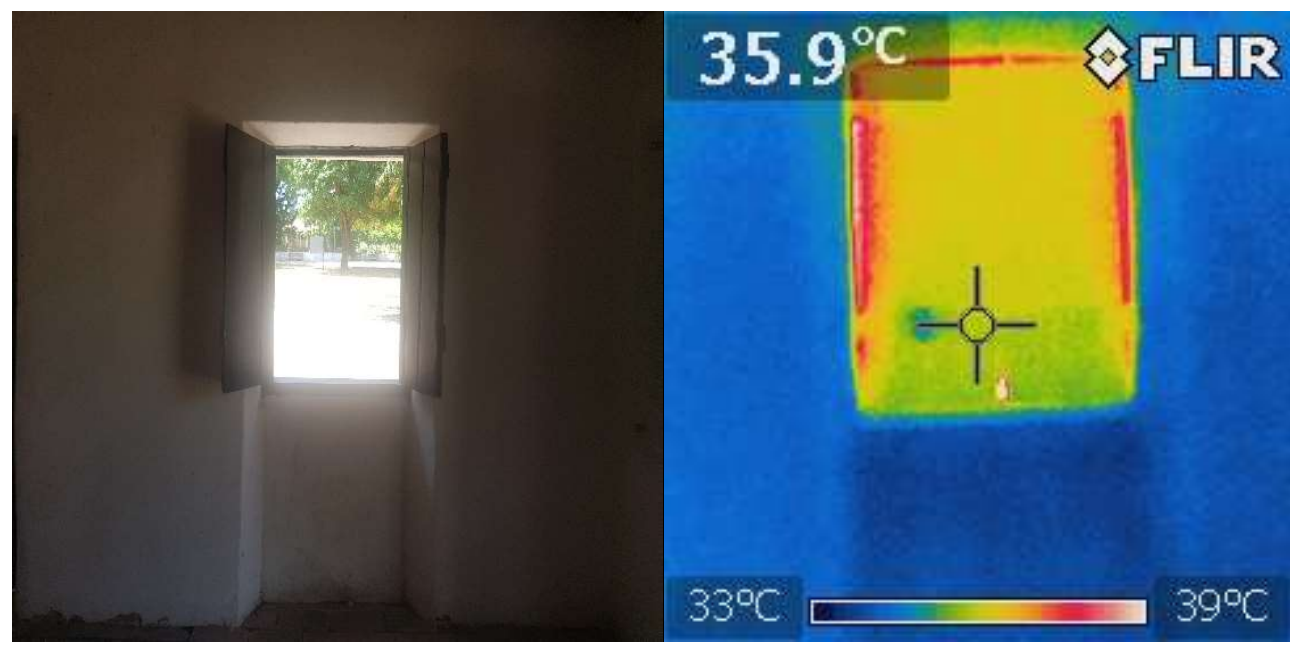

Figura 9 - Parede interna da sala de estar nas duas perspectivas. Fonte: acervo pessoal.

\section{Conclusões}

A temática abordada sobre patrimônio histórico é de interesse de todos, pois retrata a história de uma população, dos seus costumes e tradições. A escolha da casa de José de Alencar conta um pouco a história do povo cearense que vivia em meados do século XIX e a forma como viviam.

O estudo permitiu ver a viabilidade do ensaio termográfico como experimento capaz de identificar objetos ocultos e possíveis patologias, já que para a manutenção de um patrimônio histórico, é indispensável a descoberta de possíveis danos e a verificação do estado dos elementos estruturais, para que não haja possíveis surpresas, e para a manutenção da edificação sem que precise danificar o patrimônio, por isso se fez necessário o estudo desse ensaio não destrutivo como alternativa, dos ensaios mais usuais como o de ultrassom, e também dos ensaios destrutivos, preferencialmente evitáveis de fazer com esse tipo de edificação de valor histórico.

O método do ensaio foi de termografia passiva, onde não houve um estímulo de luz artificial, mas natural com a luz solar. Desse modo, a análise teve caráter qualitativo. A câmera utilizada foi uma FLIR que obteve termogramas, que mostravam a diferença de temperatura nas diferentes regiões da fotografia.

Portanto, a pesquisa mostrou que o método é eficiente, prático e rápido, todavia é necessário o uso de ensaios auxiliares para um diagnóstico preciso e seguro, ainda assim pra uma pré análise de possíveis patologias e visualização de elementos estruturais, ou de vedação na construção, o ensaio se tornou bastante eficiente. Na casa de José de Alencar, percebe-se, em algumas regiões, zonas de pontes térmicas que podem ocasionar patologias, como fissuras. Também foram vistos elementos que estavam ocultos na estrutura e que foram detectados pela câmera termográfica, além de na fachada posterior ter sido detectado na alvenaria na parte inferior perto do chão, uma zona mais fria, antecipando um possível foco de umidade.

A análise se tornou eficiente, porém precária em dados e detalhes, sendo de extrema importância o uso de mais métodos não destrutivos associados a esse para um diagnóstico mais detalhado. Então seria interessante fazer um estudo de ultrassom na casa de José de Alencar para adquirir novos parâmetros bem importantes para um parecer mais exato do estado da edificação.

\section{Referências Bibliográficas}


ASSOCIAÇÃO BRASILEIRA DE NORMAS TÉCNICAS. NBR 15424: Ensaios não destrutivos -Termografia Terminologia. Rio de Janeiro, 2016.

ASSOCIAÇÃO BRASILEIRA DE NORMAS TÉCNICAS. NBR 16292: Ensaios não destrutivos -Termografia Medição e compensação da temperatura aparente refletida utilizando câmeras termográficas. Rio de Janeiro, 2014.

BONAFÉ, Gabriel. Pontes Térmicas devem ser corrigidas na fase de projeto. In: Pontes Térmicas devem ser corrigidas na fase de projeto. [S. I.], 2020. Disponível em: https://www.aecweb.com.br/revista/materias/pontes-termicas-devem-ser-corrigidas-na-fase-deprojeto/11674. Acesso em: 13 jun. 2020.

CASA José de Alencar. [S. I.], 14 fev. 2020. Disponível em: https://casajosedealencar.ufc.br/pt/a-casa-josede-alencar/. Acesso em: 10 nov. 2020.

CORTIZO, Eduardo Cabeleiro. Avaliação da técnica de termografia infravermelha para identificação de estruturas ocultas e diagnóstico de anomalias em edificações. [S. I.: s. n.], 2007.

ENSAIOS não destrutivos e inspeção. $\left[\begin{array}{llll}S . & l .\end{array}\right]$ 2020. Disponível em: https://abendi.org.br/abendi/default.aspx?mn=709\&c=17\&s=\&friendly=. Acesso em: 20 jun. 2020.

FLIR. FLIR E6: FLIR E6. [S. I.: s. n.], 2020. Disponível em: https://www.flir.com.br/products/e6/. Acesso em: 15 nov. 2020.

GIL, Augusto Masiero; FERNANDES, Bruno; PRAGER, Gustavo; PACHECO, Fernanda. Análise das manifestações patológicas em uma edificação do patrimônio histórico por meio de termografia infravermelha e inspeção visual: Estudo de Caso. Associação Brasileira de Patologia das Construções, [S. I.], p. 1-9, 14 jan. 2015.

KERSUL, Guilherme Marques. Uso da termografia para inspeções e manutenção predial: Estudo de caso. [S. I.: s. n.], 2014.

MARIO, Mauro. Uso da termografia como ferramenta não destrutiva para a avaliação de manifestações patológicas ocultas. [S. I.: s. n.], 2011.

MENDONÇA, Luís Viegas; AMARAL, Miguel Martins do; CATARINO, Pedro Soares. A termografia por infravermelhos como ferramenta para auxilio à inspecção e manutenção dos edifícios. SPY BUILDING, [S. I.], p. 1-23, 2013.

RISSARDI, Crystian; PASTLAFF, Jeferson Ost; MEZZOMO, Paulo. Aplicação da termografia na inspeção de fachadas de edificações históricas em madeira. CBPAT, [S. I.], p. 1-9, 1 abr. 2016.

USP, Esalq. Radiação Térmica. In: RADIAÇÃO Térmica. [S. I.: s. n.], 2020. Disponível em: http://www.ler.esalq.usp.br/aulas/lce200/Cap3.pdf. Acesso em: 7 jul. 2020.

VALE, Clara P.; VENCESLAU, Ruben; PEREIRA, Luís Bravo. Imagens multiespectrais e termográficas aplicadas ao estudo de Património Arquitectónico. Congresso da reabilitação do Patrimônio, [S. I.], p. 205-214, jun. 2017. 